\title{
A BETAMALE IS BEING BEATEN
}

Ivan Knapp

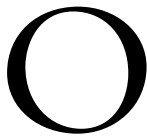

n 25 September 2013 an embedded YouTube link was posted anonymously, and to the considerable surprise of other users, on the $/ \mathrm{mu} /$ (music) forum of the notorious image-board site 4 chan. One 'anon', seemingly impressed by the way its imagery deftly synthesizes obscure internet subcultures, declared that this poster clearly 'knows his audience', another questioned whether whoever made this video might be 'shit talking my shitty lifestyle'. ${ }^{1}$ The first in a trilogy of short films by the Canadian artist Jon Rafman that explore what he calls 'the murkier corners of the Web', and the only one to be first shown online, Still Life (Betamale) opens with the word 'PLAY' flashing in green at the top right corner of the screen whilst a man in a pink suit points at the viewer. ${ }^{2}$ The gesture is followed by a medley of found material - video, anime stills, screenshots, photographs taken from webcam footage, recordings of retro gaming, message board memes, specialist manga channels, fetish community sites - which, the title suggests, comprise an attempt to survey what we might understand as the visual culture of the betamale. The figure of the betamale, a constitutive other to the macho 'alpha', necessarily overlaps with the involuntary celibate or 'incel' subculture which has received increasing media attention since Elliot Rodger killed sixteen people in Isla Vista, nine months after Rafman posted Still Life on 4 chan. ${ }^{3}$ Emerging from the same subcultural online milieu, the incel and the betamale denote similar assumptions about masculinity and femininity, sexuality and violence. The latter's presentation, one might say portraiture, in Rafman's work therefore provides an opportunity to examine the relationship between a particular subculture and the political and sexual violence it might endorse, in particular, what that subculture makes available at a visual level to the subject in the register of fantasy as it is mediated by new technologies. 


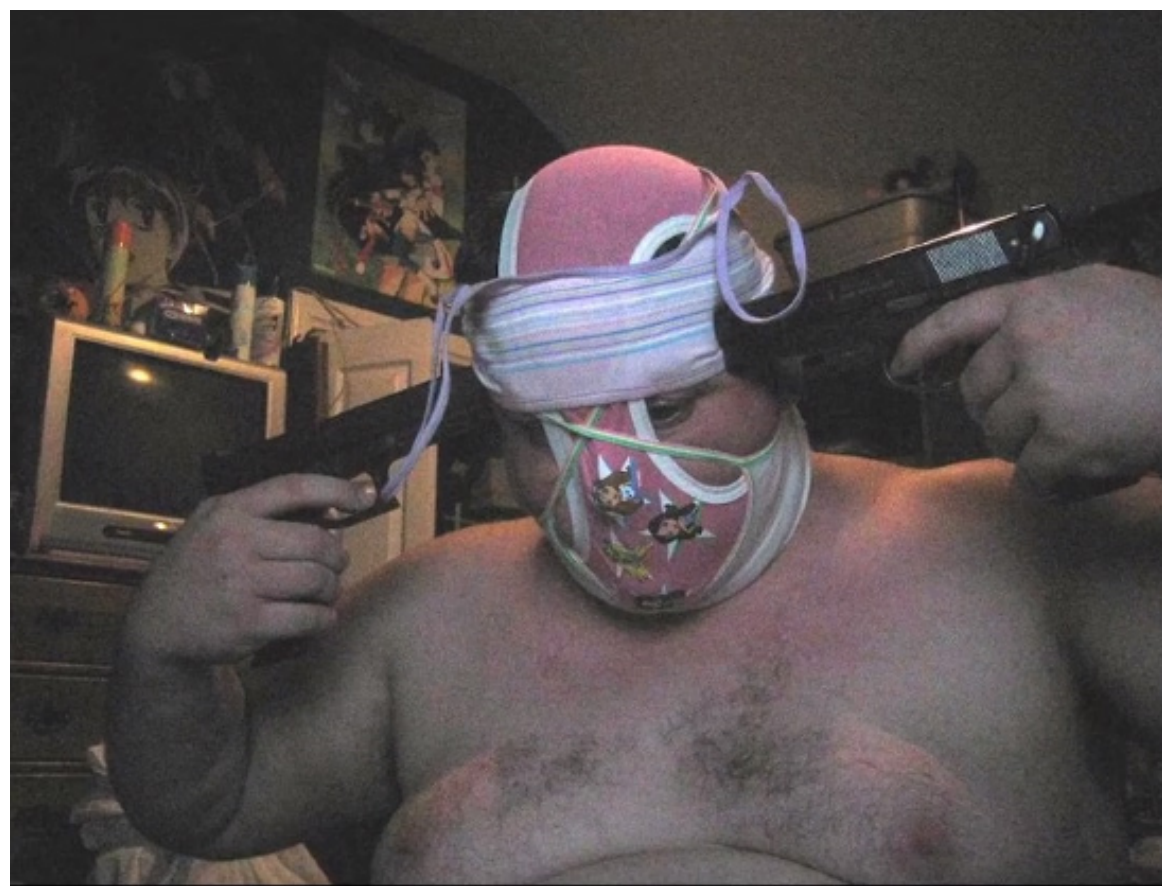

Figure I Jon Rafman, Still Life (Betamale), 20I3. Single channel video. Photo: screenshot.

At the beginning and the end of the film, Rafman lingers on what is, to my mind, the most arresting image of Still Life, first zooming toward the perimeter of the frame before reappearing and then fading to black at the film's dénouement (figure I). It shows a grainy photograph of an unknown man with an assortment of clothes wrapped around his head in the manner of a bondage mask whilst he holds a revolver to each temple. The man is obese and shirtless, the size, colour and pattern of the underwear suggest they belong to a young girl. The room he is sitting in is dark and cluttered with the debris of a teenager's bedroom. Posters behind his head show characters from manga animations which will feature heavily throughout the rest of the four minutes and 54 seconds of the video. In the following passage more low-res photographs of dark, mostly fetid, rooms are presented in a slideshow. Typically they contain a configuration of a bed and a monitor arranged for the purpose of spending prolonged periods of time at the computer. The video takes a keen interest in the abject condition of these lairs, hovering 


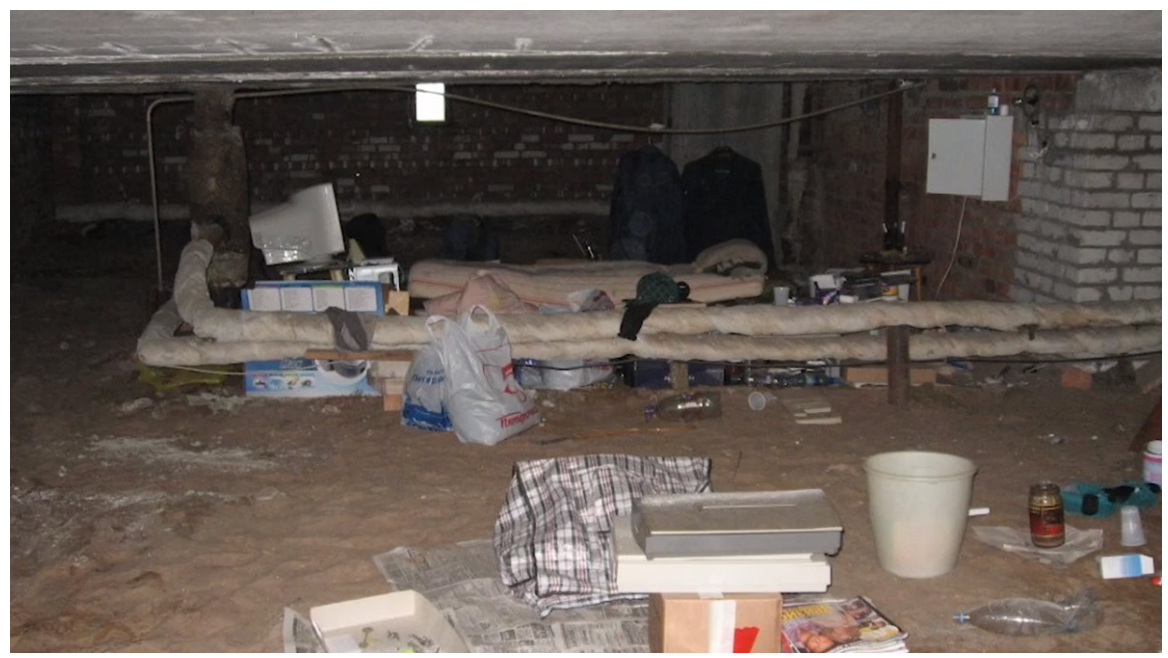

Figure 2 Jon Rafman, Still Life (Betamale), 20I3. Single channel video. Photo: screenshot.

over keyboards covered in a morass of congealing food matter, drinks cans, bucket toilets, cigarette butts and discarded pizza boxes.

Exiting these chambers Still Life transitions into what might be seen on the screens they house: found footage and animations drawn from niche roleplaying subcultures of the type that suggest extreme commitment and devotion from users congregating in some of the more esoteric corners of the internet; furry fandom featuring animal anthropomorphic pornography; masked young women dressed as anime characters performing seductively for a camera; scenes taken from hentai pornography - a genre notable for its staging of fantastical sexual encounters between humans and nonhuman characters and objects - as well as graphic gestures to numerous other fetishes. Overlaying the images, a synthesized voice-over tells us that 'whatever shift in your spiritual life occurs, fragments such as these surface' (OI:27). Approximately two-thirds of the way through the video, images of a profoundly violent nature crescendo by way of a montage sequence in which a series of brutal pictures, mostly taken from anime, rapidly appear and dissolve into each other in a radical break from the rhythmic continuity of the rest of the work (in which we are also shown images of mutilated and melting bodies, two hanging scenes and one of a character dressed as a fox drowning slowly in mud (figure 3 )). 


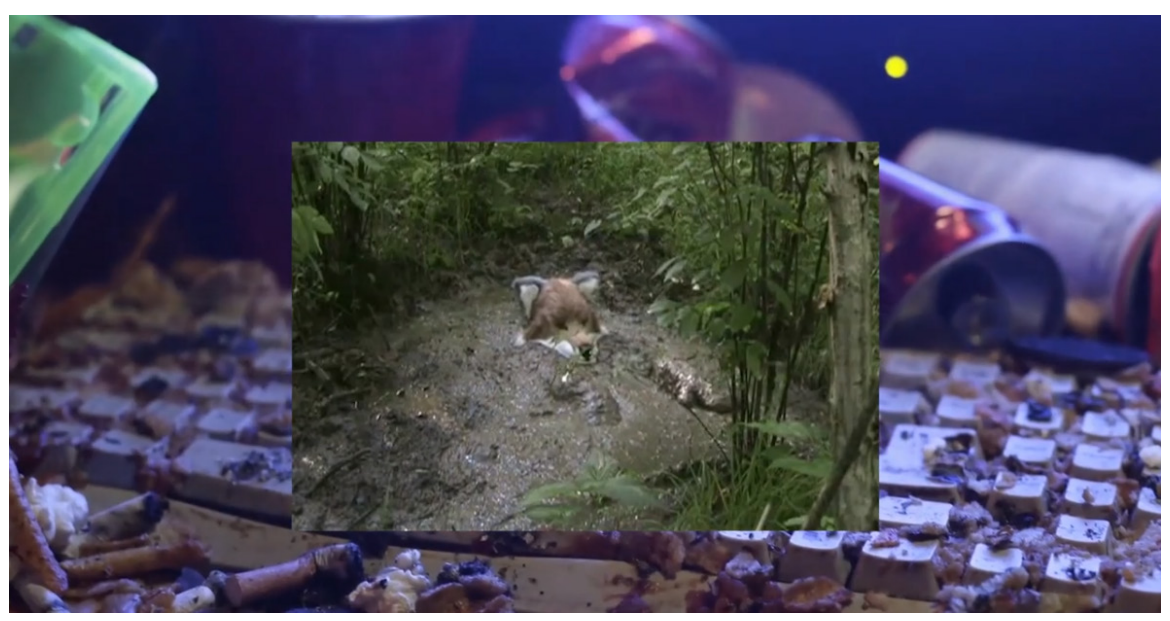

Figure 3 Jon Rafman, Still Life (Betamale), 20I3. Single channel video. Photo: screenshot.

The exoticism of this spectacular fantasia is startling, however what emerges most consistently from its awful pageantry is a tapestry of motifs in which sex and violence not only appear bound in over-proximity but are couched in the cultural forms of genres which make an express appeal to childhood fantasy and entertainment, whether in the form of infantilised anime characters, dressing up as cuddly animals or by reference to the antisocial environs of a teenager's bedroom. Speaking at the exhibition of Still Life at the Zabludowicz Collection in London, Rafman made space for psychoanalytic theory as a tool with which to probe his material, observing that 'in the various subcultures I reference, there is something infantile in that their desires are base and regressive as well as in the sense that they're simply returning to the original desire, seeking those pleasures through the screen'. ${ }^{4}$ Whilst this discussion is more concerned with the particular relationship between subjects and subculture set up by the work being originally addressed to 4 chan users, rather than the ways in which its subsequent exhibition in spaces such as the Contemporary Art Museum St. Louis and the Stedelijk Museum were framed by physical installations that cocooned his audience in womb-like structures, the notion of an intransigent desire, both general and particular, lodged in infantile sexuality speaks directly to what I propose is at stake in the work.

If, as the voice-over proposes, we are to treat the video as a dream or at 
least a reverie into fantasy, it is an offer I would like to take up by parsing what one could call Still Life's manifest content through the psychoanalyst Juliet Mitchell's re-reading of Sigmund Freud's 'core' masturbation fantasy set out in Siblings: Sex and Violence. 'A Child is Being Beaten' was the subject of Freud's I9I9 paper of the same name and comprises three stages which differ for girls and boys. The first phase is 'completely represented by the phrase: 'my father is beating the child", a child, Freud emphasises, that the fantasist hates. ${ }^{5}$ In the next scene 'the person beating remains the same (that is, the father); but the child who is being beaten has been changed into another one and is now invariably the child producing the phantasy', a configuration neatly represented by the statement: 'I am being beaten by my father'. ${ }^{6}$ But this second phase, 'the most important and the most momentous of all', is nevertheless a 'construction of analysis' inasmuch as it is never remembered. ${ }^{7}$ The third and final scene resembles the first with two important distinctions, the first being that the beating figure is now only a 'representative of the father, such as a teacher' and, secondly, that the child being beaten is no longer the fantasist. ${ }^{8}$ Instead the victim has been multiplied into a number of other children who are, significantly, 'not personally known to the subject'. 9 From this tripartite structure Freud warns of the variability and complexity of the fantasy's 'alterations and elaborations' both in regards to its form and the precise nature of the punishments and humiliations it stages. ${ }^{10}$

Significantly for Mitchell, the fantasy is one in which siblings may be granted a prominent role. Although Freud, as well as later analysts, situate the fantasy within the frame of the oedipus complex, presenting its narratives as an expression of rivalry between siblings for the exclusive love of the parent of the opposite sex, Mitchell's analysis prefers to lay emphasis on the crucial 'fact that the fantasist does not occupy one position only: as in a dream, she or he inhabits all the characters, is beater and beaten'. ${ }^{11}$ This mobility, in the slippage through the stages, in the carousel of characters who are constantly exchanging places and, most explicitly, in the final scene in which a host of anonymous children 'not personally known' are being beaten, is essential to the oscillation between sameness and difference as the pivot on which Mitchell's theory of sibling relations rests. ${ }^{12}$ According to this account, the expected imminent arrival of a sibling carries an existential threat to deprive the infant of its unique subject position within the family unit. ${ }^{13}$ The problem is one of recognition, of recognising the 'difference in 
sameness' and understanding that the new arrival may stand in the same place and that therefore the infant subject must forge the differences that allow seriality to then unfold. Mitchell begins and ends her chapter on this fantasy with the phrase 'looking sideways', a direction of the gaze deployed to both register her departure from oedipal orthodoxy and to signal the presence of another on the lateral axis of whom we must be aware. The enjoinder is to look both ways, to find a productive reciprocity in being placed side by side and therefore to acknowledge the influence of lateral groups, which find their prototype in the sibling situation, on the development of sexuality. To which end, her theory would seem an apposite intervention for addressing the ways in which Still Life stages infantile sexuality crossing over to the realm of the social, or more precisely, subcultural peer groups. And, perhaps, further toward positing the ways in which technologies provide new covers for both articulating and disguising fantasies that can be traced back to certain psychic events which inhere in the formation of lateral groups.

By privileging the significance and intensities of the sibling relation, Mitchell's theory might encourage us to speculate on what would occur between sisters and/or brothers when the parental prohibition on lateral incest and violence is absented. To a certain extent, 'A Child is Being Beaten' offers just this sort of scenario with its display of corporeal punishment taking place in the realm of a very early fantasy that originated during a phase of infancy when parental prohibition had not yet achieved its full psychic efficacy as a censor on desire. To borrow from the language of dream-work, it endows a displacement with the conditions of its representation, which is to say it gives pictorial form to a desire to murder that stems from the threat of the sibling being replaced. ${ }^{14}$ For Mitchell, the beating must be understood to articulate the desire to annihilate the intruding other. And yet, such is the struggle to differentiate between oneself and the new arrival - an arrival who is to occupy the same position by which the infant orients all their relations to others and their self - the 'you' is liable to collapse into a 'we' as we see in the third stage of the fantasy. It is because, 'at the level we are addressing, sisters and brothers are the same', with 'narcissistic love [underlying] the thought of reduplication', that the sequencing of sadism and masochism which marks each stage of the fantasy as traced by Freud are held far more tightly together. ${ }^{15}$ As such, the eradication of the ego and the eradication of the other are essential preludes to the satisfaction of the autoerotic subject for 
whom the subsequent anonymous others of the third stage are nothing more than duplicate stand-ins. ${ }^{16}$

Anonymity, or rather the eradication of identity as a precondition for play and for punishment, pervades Still Life. The anime masks and the furry suits, whatever else they signify about whoever wears them - and many roleplaying subcultures develop highly sophisticated and nuanced systems of character development and personalisation - nevertheless represent a concealment within which lies their appeal as a masquerade by which to shuttle between subject positions and defy the barriers of difference. More specifically, it is the intrusion of such graphic fragments in concert with the repudiation of any fixed contours between available personas, or rather the apparent availability of all personas (who, for example are, or is, all those bodies melting in the swimming pool? (figure 4)), that suggest not only the imprint of a repressed fantasy but a visual schema for accommodating for its restaging. Thus, in the case of anime, the mask worn by Rafman's costumed performers is drawn from a highly schematic genre of representation in which the feminine 'ideal' is one in which only the most minimal difference in physical appearance is tolerated. Even the rooms in which these performances are staged serve to emphasize the eradication of specificity, each taking place in a corner of what appears to be unoccupied office space, and which could scarcely be

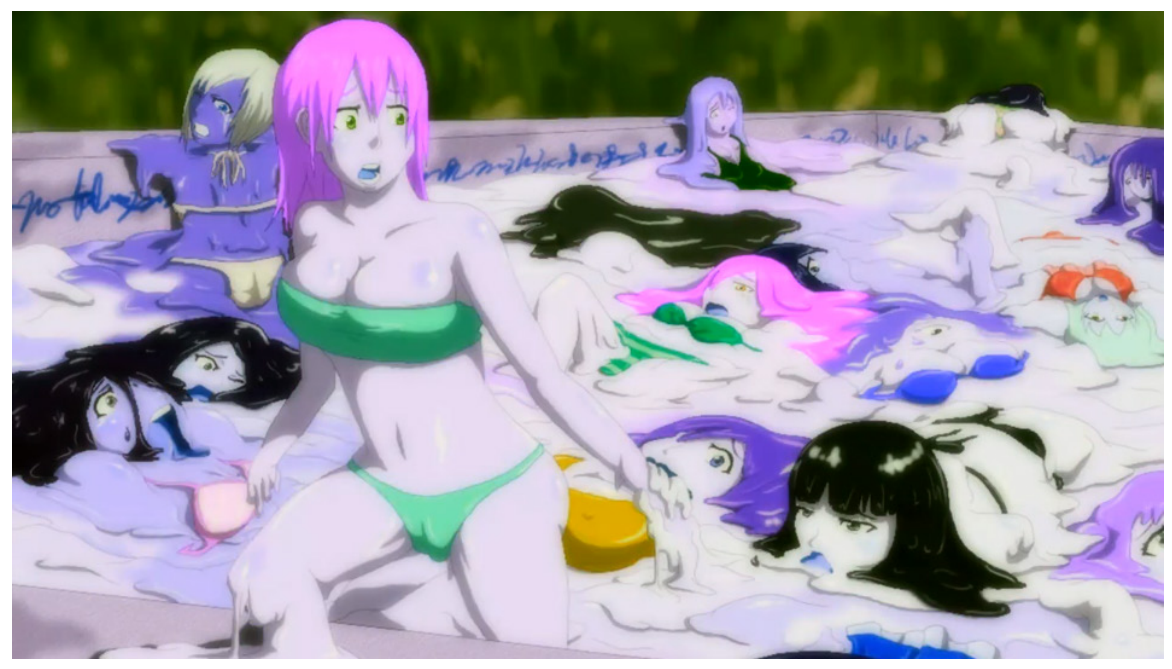

Figure 4 Jon Rafman, Still Life (Betamale), 20I3. Single channel video. Photo: screenshot. 
more generic. Mitchell uses the designation minimal difference to describe the condition of sibling sexuality and violence, one that is vulnerable to a threat of over-proximity, a too much-the-same between brothers and sisters that undergirds their explorations of lateral incest and violence whether in fantasy or in reality. This tension is also crucial for the transpositions of the beating fantasy and the peculiar character with which autoeroticism is made social through the progression of its scenes. However, if the 'not personally known' cast of children in the fantasy can speak to the sexualised anonymity of young women wearing anime masks, what can be made of the characters in Rafman's film, such as the wolf, the fox, the two bears and the koala, whose costumes are drawn from different species altogether?

In thinking about the relation between the sameness of the anime characters and the difference represented by the furry fandom role players - inasmuch they appear to at least indicate a difference between the human and nonhuman, no matter how generic - we might turn to the paper Anna Freud wrote on the beating fantasy only three years after her father's. ${ }^{17}$ It describes the case of a fifteen year old girl who could not accept the connection between her textbook beating fantasy and an elaborately constructed set of daydreams which had subsequently been cultivated to replace it. ${ }^{18}$ Anna Freud aimed to demonstrate the extent to which the 'artistic superstructure of daydreams' is also constructed on this fantasy and frequently used to conceal it. The sexual and violent content of the fantasy is thereby sublimated into 'nice stories' which reveal the way in which we all, as Jean-Paul Sartre said of Jean Genet, 'awake without ceasing to dream'. ${ }^{19}$ Sartre's argument claimed that Genet's writing was a form of onanistic narcissism and that the words themselves 'finished the job'. For the adolescent girl in Anna Freud's paper too, the words in these stories are sexually satisfying in themselves and for Mitchell this would 'indicate the presence of a neurotic symptom' that is inconsistent with the younger Freud's conclusion that the nice stories are the product of sublimation by which the sexual content of the fantasy has been worked through and transformed into an artistic enterprise. ${ }^{20}$ Rather, the fantasy is converted into nice stories which, by Mitchell's view, 'apparently, but only apparently, contain care and affection'. ${ }^{21}$ Mitchell's divergence from Anna Freud on this point owes to her insistence that a fantasy can only be sublimated if it is relinquished after a recognition of its wish-fulfilling elements, a process that cannot be said to have been achieved if the story 


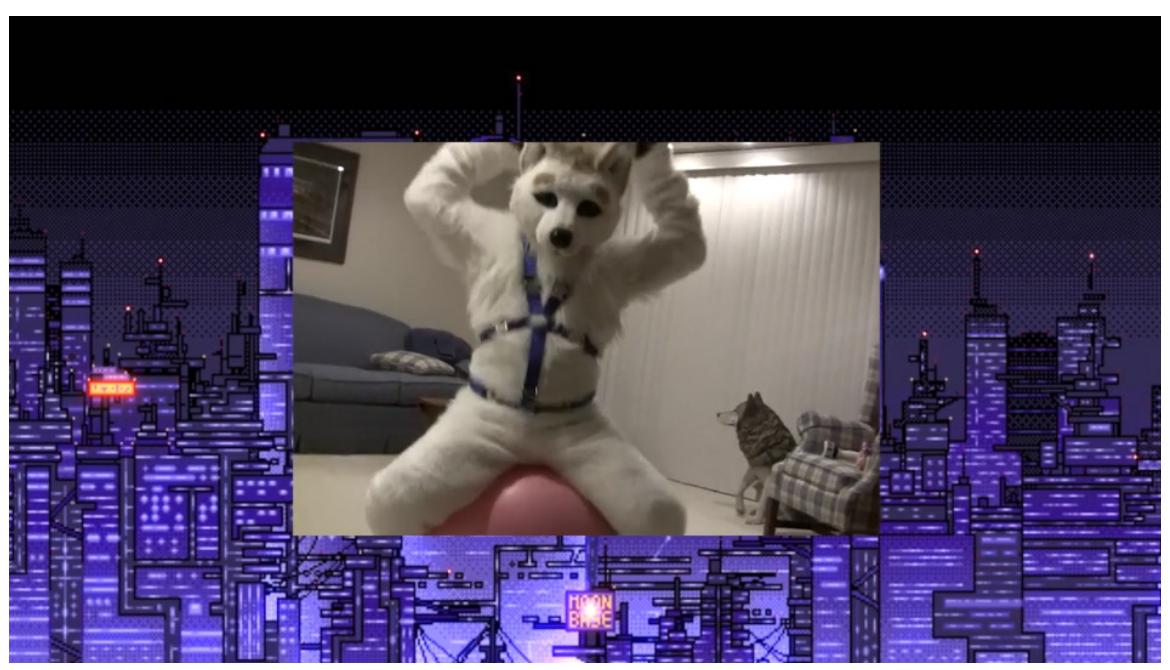

Figure 5 Jon Rafman, Still Life (Betamale), 20I3. Single channel video. Photo: screenshot.

retains its capacity to stimulate pleasure whether through masturbation or in fantastical daydreams.

Mitchell leverages this disagreement to underscore her contention that ' $A$ Child is Being Beaten' is, in essence, a hysterical fantasy which through its universality points out the potential hysteric in all of us. The stories which are produced to disguise its presence would therefore also signal the fantasy undergirding other categories in which narrative is used for the fulfilment of wishes. One such category might be the 'saccharine fairy tale', a genre in which infantile sexuality and its satisfaction is given license to surrender reality to the superior force of the imagination. In these magical worlds a cast of characters, human and non-human, serve as screens behind which is deposited otherwise troubling infantile desire. A refusal to give up these fantastical stories and their cast of characters would therefore indicate that the fantasy they were constructed to conceal retains its erotic power, a situation that could be illustrated by the image of an anthropomorphised green unicorn kissing a young girl (figure 6). From here, Still Life's menagerie can be read as a set of characters which betray the presence of the beating fantasy at work in intricate subcultures which refer to genres that tell much more elaborate 'nice' stories. As such, the slippage, between the superficial innocence of furry fandom and the bizarre eroticism of 'yiffing', between the nice story 


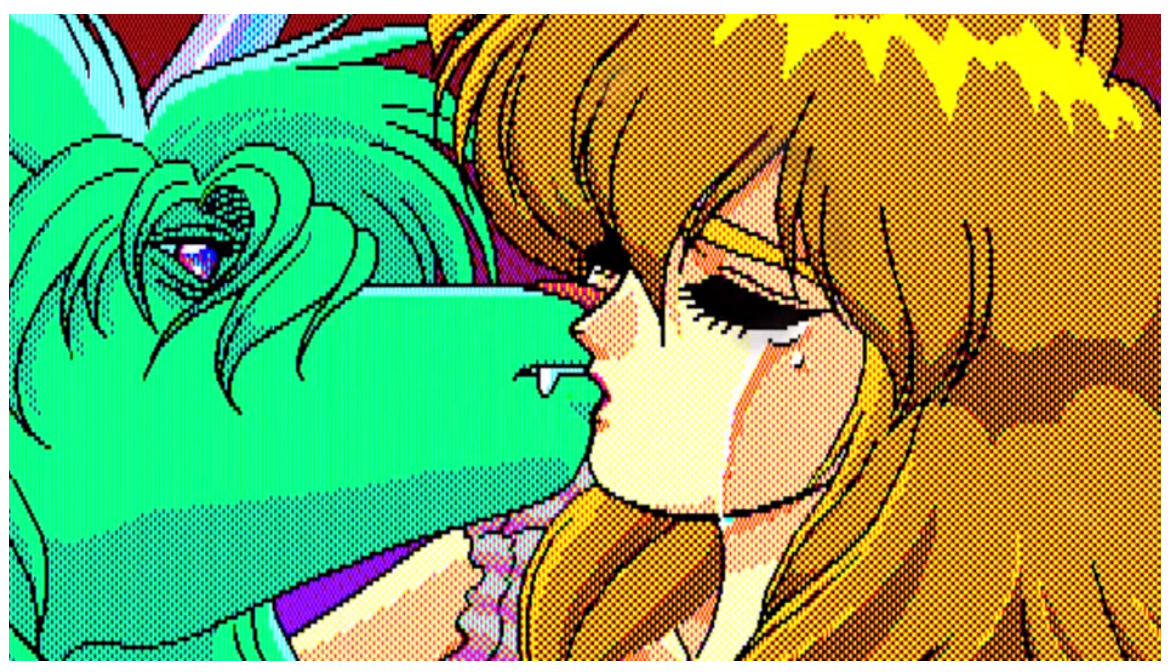

Figure 6 Jon Rafman, Still Life (Betamale), 2013. Single channel video. Photo: screenshot.

and the sex and violence of a 'A Child is Being Beaten', would indicate the psychic trace of a core fantasy the subculture, like the daydream, labours to conceal. $^{22}$

For Anna Freud's young patient, each episode of the stories she created would reach a point of climactic tension that diffused into a feeling of happiness. ${ }^{23}$ Although, as a substitute for the orgasm brought about from masturbation to the shameful beating fantasy, the stories were not always infallible. The narrative structure of the daydreams served to underscore her father's insistence that fantasy is a mode of creative thinking dominated by the pleasure principle. The masturbatory act of the fantasying child is characterised by pressure and tension, what Mitchell describes as 'the pulse beat of the excited clitoris or penis'. ${ }^{24}$ These sensations which accompany the first developments of the fantasy endow it with a rhythmic structure extending from the physiological to serve as something of a support for the pictorial scenes which are summoned up. Rafman's video makes use of a similar non-visual support by way of a soundtrack by his collaborator Daniel Lopatin (a.k.a Oneohtrix Point Never). ${ }^{25}$ As with Mainsqueeze (20 I 4), which along with Erysicthon (20 I 5), completes the three-part exploration of internet subculture Still Life initiated, the music is almost entirely constructed of alternating sonic pulses and waves that punctuate the video's transitions. 
Yet there is no swelling climax here - nothing that would suggest of itself the steady build and release of orgasm - Lopatin's soundtrack is for a more prosaic, weary or numb form of masturbation, carried out in the vague hope of sating some not quite conscious urge. The grainy photograph of a man holding guns to his head reminds us, if it were necessary, that the aftermath of onanism in both the beating fantasy and the video, is guilt - a feeling that will be 'more strongly excited', Sigmund Freud observes at the beginning of his paper, in cases in which this core fantasy takes on the characteristics of an obsession; say, in the form of a fetish. ${ }^{26}$

Masud Khan, a protégé of Anna Freud, wrote of the 'illusion of omnipotent control' found in the fetishist's desire for mastery over 'magical objects', the kind of control we might imagine is afforded by the casual and arbitrary power to make fantastical erotic bodies appear and disappear, transform and mutate at will just by a few clicks. ${ }^{27}$ In classical psychoanalysis, however, the fetish object is always 'a substitute for the woman's (mother's) penis that the boy once believed in and does not want to give up'. ${ }^{28}$ Inevitably this entails that the traumatic threat which lends the fetish its agency is routed back to the symbolic annihilation of castration which, in in Freudian and Lacanian theory, is the only way the unconscious is able to represent death. ${ }^{29}$ One of the many productive aspects of Mitchell's theory is that it allows for an additional psychic representation of death in which death or annihilation is figured by the sibling's threat of displacement and the complete effacement of one's subject position. It is this unbearable prospect that she terms the sibling trauma. Accompanying this theoretical contribution, Mitchell postulates what she has provocatively termed the 'Law of the Mother'. Preceding Lacan's 'Law of the Father', this injunction prohibits violence and incest between siblings on pain of the total withdrawal of protection and care $-\mathrm{a}$ threat perceived by the infant to be 'tantamount to a death'. ${ }^{30}$ Returning to the beating fantasy, we might find a transgression of both laws facilitated by their suspension in fantasy. If anonymity, and with it the collapse of minimal difference, pervades Still Life, more familiar signs of death and taboo are even more insistently and explicitly present. The most florid evocation of paternal law may be found in the second hanging scene (figure 7), in which highly sexualised and anthropomorphic dogs in Day-Glo hues are strung on a gibbet for the transgression, or so we might venture, of desire cutting across proscribed categories. 


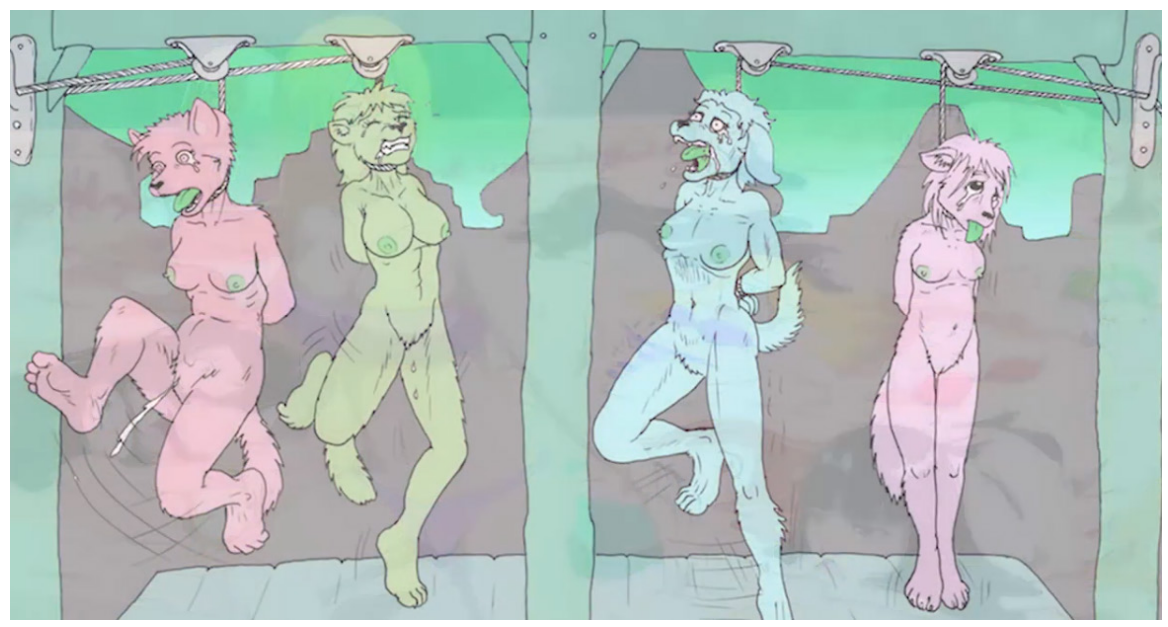

Figure 7 Jon Rafman, Still Life (Betamale), 2013. Single channel video. Photo: screenshot.

Khan argued passionately and persuasively for the complexity of the therapeutic function of perversions. ${ }^{31}$ Nevertheless, on the subject of pornography he was far more unequivocal, attacking its cultivation of depersonalisation, dissociation and violence. ${ }^{32} \mathrm{I}$ would suggest his rebuke might gesture at a too dangerous correspondence between pornography and infantile sexuality, a correspondence that risks the infiltration of the former, through the authority of the latter, into otherwise distinct modes of cultural production. The basis of this relation would be found in a preference for stasis, a regressive pull that derives its strength from a wellspring of infantile sexuality. Hence why it is Khan's observation that pornography's 'time is the perpetual and static present', and that therefore it possess a distinctly 'nostalgic atmosphere', which I would like to consider here in relation to the function of technology in the video. ${ }^{33}$ What the origin of the beating fantasy in childhood helps us to see in Rafman's work is the way that, from the very title onwards, the anachronistic technologies pictured in Still Life outmoded CGI, heavily pixelated graphics, games consoles from the I990s - are positioned as always looking backwards, animating and bringing to life fantasies of, and for, the past. Whatever their forward thrust may have once been, these technologies are presented as tools which can only access desire in reverse, tools of regression as much as progression - the performers in anime masks, beyond their pitch to the uncanny, are afforded a spectral 
quality as the traces of their movements are caught in slow motion. This is perhaps close to what Rafman has in mind when he talks of his interest in how 'technology in its broadest sense ... changes the way in which we remember ... changes the way we actually conceive of the past'. ${ }^{34}$ If, for Sigmund Freud, desire in fantasy is always nostalgic, Still Life would seem to propose a set of technologies appropriate for its expression, appropriate at least for a particular subject who may be fixed and formed by his, and in this case it is a 'his', memories and manipulations of these devices. These are, then, nostalgic devices by which to access nostalgic desire. In other words, something of a dream media that instates the dialectic between novelty and obsolescence, a relay in which desire is always outstripping its object, within the oneiric analogy of dreams as apparatus by which we revisit the psychic territories of yesterday; as though a certain constellation of visual and information technologies, clustered around the graphic user interface as a site of mastery profoundly geared toward the slippage between fantasy and reality, serve as repositories for past desires and as such, like dreams, offer a vehicle for their re-mediation.

As a genre of media whose destiny is pre-programmed obsolescence, consumer computing technology provides an array of felicitous screens on which to render the 'shadow show' cast in the psychical space of dreams. ${ }^{35}$ The voice over in Still Life incants that we are indeed 'again in a dream' (O3:4 I), that 'the images captivate you, but you still drift off' (OI: IO). We 'can still see every detail clearly but can't grasp the meaning' (or:I7). The direction of travel is made clear, we are moving back to 'the womb, the original site of the imagination' (oo:36), a point of eternal return before one is dethroned and displaced by the intrusion of another. As with the other works in this series, the dream 'fragments', as Rafman calls them, are dredged from the 'deep internet' from whose murky depths they draw some kind of psychic authenticity. ${ }^{36}$ Often the clips of costumed performers are inlaid against a highly stylised and non-descript backdrop taken from some animation or other and from which they seem to float hypnotically toward the viewer, as if to emphasise their origin in a world that will remain alien and exotic (figure 8). What the exchange between footage of 'real' performances and animations seems to be pushing against is any meaningful distinction between the two, the footage of fetishists performing to webcams is digitally captured and compressed into a standard file format which can be trafficked across 


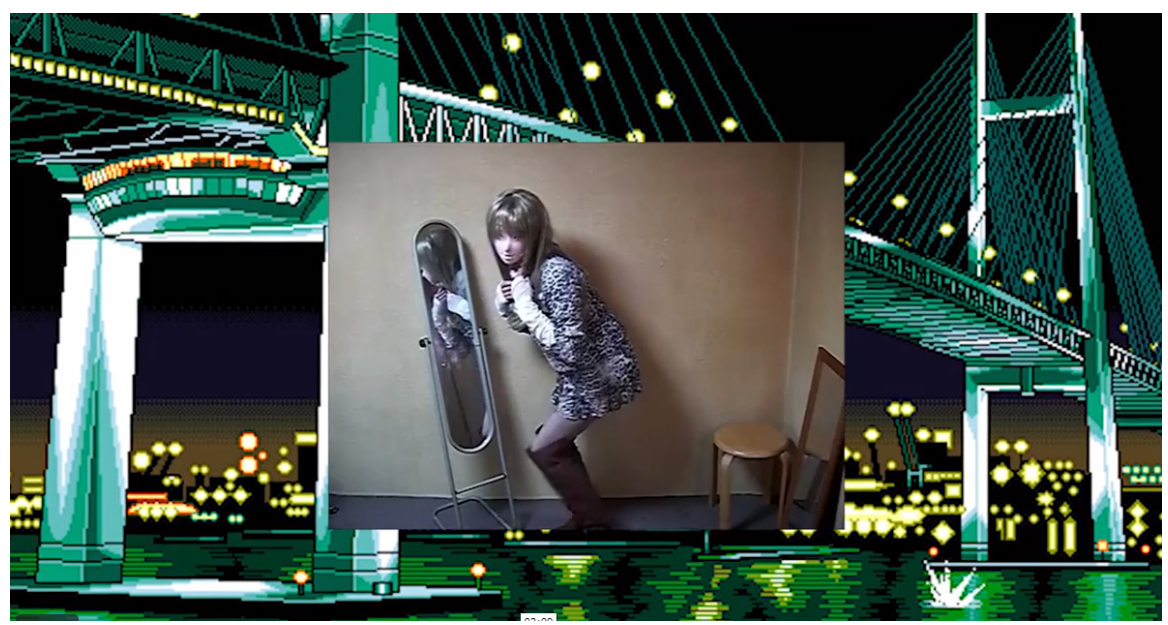

Figure 8 Jon Rafman, Still Life (Betamale), 2013. Single channel video. Photo: screenshot.

the network before being opened by another user - the bodies and artefacts that are extracted from the file are received as set of equivalent modular objects remotely generated and all the more remote for it. Wrenched from their ground (another displacement), a sense of shared material distinction or analogical relation is lost as contextual reality is subsumed by the highly subjective workings of fantasy. Symptomatic of what has been understood as digital image production's attack on the authority of the referent, the proximity of cartoon violence to the threat of physical violence in Still Life points to the dangers of dismantling in their entirety the conceptual borders between media as technologies that each carry an evolving set of challenges to representational systems in the context of online fantasy. ${ }^{37}$

Whilst in Mainsqueeze and Erysicthon the artist's gaze is less explicitly drawn to the graphic display of fantasies online, it is the nature of the 'field work' presented by Still Life which most acutely calls into question Rafman's anthropological posture - a stance not uncommon among artists whose work has been parcelled under the 'post-internet' category' - as it might be addressed by a psychoanalytic understanding of fantasy. More explicitly, and beyond the question of whether Rafman offers complicity or critique, the material the video lays claim to can be seen to make more clearly visible the psycho-dynamics of fantasy as that which connects niche subcultures to 
much broader political narratives. Therefore, it is at this point that I want to reencounter the image of the man with two guns pointing at his head. Rafman forces us to revisit this character throughout by inserting the image ten or eleven times between the beginning and the end of the video, providing it with a ground - the video as a discursive object of contemporary art - that overlays, obscures and mystifies the context in which it was first posted to the internet and the specific situation in which it was produced. In the absence of that information, the door to morbid conjecture is opened at the artist's direction. Rafman retains control of what inferences which may be drawn and so sets the parameters of any speculative narratives in which the viewer may choose to insert the image and its protagonist; what act has preceded this image and what will happen next? Despite its ostensible portraiture, Rafman's use of the image as an emblem of and for the video encourages us to consider it the titular reference. Throughout most of this discussion I have abbreviated the title of the work to Still Life, leaving aside the parenthetical reference (Betamale) which stands after and behind it. However, this still life, which we must surely read as an intended archetype, compels us to consider where this figure should be positioned within the sex-and-violence fantasies that the film surveys. He is both addressed by the film, most explicitly in the voice-over directed at a 'you', and the supposed author of the fantasies; a figure of masculinity standing in for a subject position and a subculture tethered to the substitution of embodied objects of desire with online proxies and fantasies which imaginatively diversify archaic tropes of domination and submission in novel dress. ${ }^{38}$ As such, Rafman's decision to release the work on 4 chan, a site that has been crucial for the evolution of terms such as 'betamale' and 'incel', carries with it the further suggestion that the primary position of spectatorship for Still Life contains a coercive identification which necessarily prescribes a certain audience. In other words, author, subject and viewers are condensed into a single figure.

In Mitchell's summary of the chapter 'A Child is Being Beaten', she describes sibling sexuality, that is, pre-oedipal sexuality, from a psychoanalytic perspective as a question of gender rather than sexual difference. Thus, like pornography, it is more concerned with the availability of multiple subject positions within the realm of sexuality than it is with reproductive sexuality. ${ }^{39}$ In one of only two references to the internet in Siblings, Mitchell expresses her doubt that a user is vying for parental attention when they look for violent 
and sexual masturbation fantasies online. ${ }^{40}$ Later on in her discussion of the beating fantasy this suggestion is developed by way of a striking conclusion which stems from the observation that it is because the fantasised beaten child never grows up that it is probable the fantasy originates in childhood. In light of this, child pornography is particularly dangerous 'precisely because it uses actuality for what should be kept as fantasy ...

If we all have somewhere a version of the fantasy 'a child is being beaten' emanating from the sex-and-violence excitement of our childhood sibling and peer histories interlocking with our physiological stimulation, then it is this very fantasy that is being appealed to in child pornography. Because the pornographer uses actuality, there is a danger that the viewer could also slip between fantasy and reality'. ${ }^{41}$

Here we seem to be approaching what might be at stake in the tropes of a subculture for whom identification and belonging is premised by a dependency on digitally mediated objects for sexual gratification, the urgency and costs of which have been made visible from the vantage point of our present moment. ${ }^{42}$ Psychoanalysis was inaugurated by Sigmund Freud's transposition, from reality to fantasy, of a scene of child sexual abuse through which, via the abandonment of the seduction theory, infantile sexuality emerged. ${ }^{43}$ Just over a century later Mitchell's warning of a universal fantasy lodged in infantile sexuality, from which it cannot wriggle free, meets with technologies that corrode the shared reality by which 'actuality' is upheld. Such a development is, on the one hand, amenable to the concept of psychic reality which mitigates against the divide between actuality and fantasy yet, on the other, the absolute dissolution of this partition also leaves one vulnerable to an incarceration that entails in a flight from reality, to be, as Donald Winnicott put it, 'locked in the fixity of fantasying'. ${ }^{44}$ It is from this imprisonment that the social is revisited as a terrain in which others are subject to the consequences of desires that have broken free of the prohibitions that seeded them, as the place where violence will be eventually committed. If, as Khan once remarked, 'pornography is the stealer of dreams' then what residues of daily alienation does it turn back into actuality in the case of self-identifying betamales? ${ }^{45}$ As a 'static enclave', an ur-pornography, in which, like Peter Pan, one never grows up, 'A Child is Being Beaten' 
establishes the wish to annihilate at the base of fantasy, that is, at the base of a mode of thinking from which action and its creative or destructive impulse springs. That the visual culture of the betamale, as presented in Rafman's film, does not or cannot sublimate the fantasy, merely converting it into a very thin disguise, leads back not just to this annihilatory wish and its infirm containment in fantasy but to the infirm containment of fantasy itself.

\section{Notes}

I am grateful to Mignon Nixon and Juliet Mitchell for their invaluable advice, as well as Cadence Kinsey, to whom this article owes a very special thanks.

I Jon Rafman '4chan thread' http://jonrafman.com/4chan.pdf (accessed Ioth September 2OI8).

2 Jon Rafman 'Interviews', Artforum (3 July 20I4) https://www.artforum.com/ interviews/jon-rafman-discusses-his-show-at-the-contemporary-art-museum-stlouis-47380 (accessed IO $^{\text {th }}$ November 20I 8).

3 For an introduction to the connections between 4 chan, incels and the alt-right, see Angela Nagle, Kill All Normies: Online Culture Wars from 4chan and Tumblr to Trump and the Alt-Right. Alresford: Zero Books, $20 \mathrm{I} 7$

4 Jon Rafman, exh. cat,. London: Zabludowicz Collection, 2015, p. II9.

5 Sigmund Freud, 'A Child is Being Beaten' A Contribution to the Study of the Origin of Sexual Perversions' in James Strachey (ed.) The Standard Edition of the Complete Psychological Works of Sigmund Freud, Volume XVII (1917-1919): An Infantile Neurosis and Other Works, London: Hogarth Press, I955, pp. 175-204, p. I85.

6 Ibid.

7 Ibid.

8 Ibid.

9 Ibid.

Io Ibid.

I I Juliet Mitchell, Siblings: Sex and Violence, Cambridge: Polity, 2003, p. I05.

I2 Whilst Jean-François Lyotard, amongst others, has also privileged the simultaneity of several possible positions being made available in the fantasy, Mitchell's emphasis on slippage refers to the particular identity of the characters inasmuch as they figure the challenge of distinguishing self from other that is brought by the displacing sibling.

I 3 Juliet Mitchell, op. cit., 2003, pp. I32-I 33; Juliet Mitchell, 'From Infant to Child: The Sibling Trauma, the Rite of Passage, and the Construction of the 'Other' in the Social Group" in fort/da vol. 7, no. 2, 2006, pp. 35-50, p. 40.

I 4 Jean Laplanche and J-B Pontalis, The Language of Psychoanalysis, London: Hogarth, I973/i988, pp. 389-390.

I5 Juliet Mitchell, op. cit., 2003, p. I04.

I6 Ibid.

I 7 We could also reflect on Freud's suggestion that 'wherever we find a sexual aberration in adults - perversion, fetishism, inversion - we are justified in expecting that 
anamnestic investigation will reveal an event such as I have suggested' (Sigmund Freud, op. cit., I955, p. I82.). However, whether the 'event' of the fantasy does stand behind any of these 'aberrations' or not, the sheer breadth of implications this radical hypothesis allows for does not necessarily help us find the specific place of this particular subcultural fetish on the lateral axis.

I 8 The relationship between the father and the daughter's work on this subject is made even more intriguing by one of the four female case studies Freud uses in his paper comes from his daughter, thus corralling the analyst into the figure of the beating father for whose affection Anna competes.

I9 Jean Paul Sarte, Saint Genet; Actor and Martyr, (trans.) Bernard Frechtman, Minneapolis, I953/20I2, p. 450 .

20 In this context, one might be tempted to speculate on the psychic significance of the prevalence of onomatopoeia in anime and manga.

2 I Juliet Mitchell, op. cit., 2003, p. 86.

22 'Yiffing' denotes explicitly sexual activity within Furry Fandom whilst, 'otaku' and 'loli', categories which also appear in the film, refer to the obsessive and almost exclusively male anime fans and the eroticisation of young girls within the genre respectively.

23 Anna Freud, 'Beating fantasies and daydreams' in Introduction to Psychoanalysis: Lectures for Child Analysts and Teachers 1922-1935, London: Hogarth, I974, pp. I37-I 57, p. I 47.

24 Juliet Mitchell, op. cit., 2003, p. I04.

25 This support is reflexive in that Rafman's work also functions as music video for Oneohtrix's track and, as such, provides a cover for its initial release on the /mu/ board.

26 Sigmund Freud, op. cit., I955, p. I79.

27 Masud Khan, Alienation in Perversions, London: Hogarth, I979, pp. I65-I67.

28 Sigmund Freud, 'Fetishism' in James Strachey (ed.) The complete psychological works of Sigmund Freud Vol. XXI (1927-1931): The Future of an Illusion, Civilization and its Discontents, and Other Works, London: Hogarth, I97I, pp. I47-I 57, p. I 52.

29 Juliet Mitchell, op. cit., 2003, p. I32.

30 Juliet Mitchell, "Why Siblings? Introducing the 'Sibling Trauma' and the 'Law of the Mother' on the 'Horizontal' axis", published in German: "Warum Geschwister? Das 'Geschwistertrauma' und das 'Gesetz der Mutter' auf der 'Horizontalen' aches” in Geschwister, 7I. Jahrgang, Heft 9, September 20I7, pp. 8I2-840, p. 7.

3 I Khan's work on the subject subsequently became entangled in personal controversies regarding the nature of his relationships with several patients.

32 Masud Khan, op. cit., pp. 219-226.

33 Ibid., p. 222.

34 Jon Rafman, exh. cat,. London: Zabludowicz Collection, 2015, p. I20.

35 J-B Pontalis, Frontiers in Psychoanalysis: Between the Dream and Psychic Pain, London: Hogarth, I98 I, p. I87.

36 Jon Rafman, 'Artist Talk' at Contemporary Art Museum St Louis (20I4) https://camstl. org/video/artist-talk-jon-rafman/ (accessed I $3{ }^{\text {th }}$ September 20I 8); see also, Jon Rafman, op. cit., 20I5, p. I9; Rafman's interest in Freudian dream theory is made explicit in his 'Dream Journal' CGI animation, 20I 5-20I6. 
37 See Cadence Kinsey, 'From Post-media to post-medium' in Clemens Apprich, Josephine Berry Slater, Anthony Iles and Oliver Lerone Schultz (eds.) Provocative Alloys: A Post-Media Anthology, Leuphana University of Lüneburg, 2013, pp. 68-83, and Rosi Braidotti, Nomadic Subjects: Embodiment and Sexual Difference in Contemporary Feminist Theory, Columbia University Press, I994.

38 Beyond the ways in which the 'alpha' 'beta' binary points out specific histories of NeoDarwinism in cyber culture (see Angela Nagle, op. cit.), the mode of address Rafman repeatedly deploys here - the 'you' - also draws in important questions regarding the role of contemporary artists and contemporary art audiences in interrogating and responding to the political challenges posed by emergent online subcultures.

39 See Juliet Mitchell, 'Foreword' in Rozine Josef Perelberg (ed.) Psychic Bisexuality: A British-French Dialogue, London: Routledge, 20 I8, pp. xvi-xxii, p. xvii; Juliet Mitchell, op. cit., 2003, pp. I I I-I29, pp. I93-225; Robert Duchinsky (ed.) Juliet Mitchell and the Lateral Axis, London: Palgrave, 2015, pp. 77-99.

40 Juliet Mitchell, op. cit., 2003, p. 89.

4I Juliet Mitchell, op. cit., 2003, p. I05.

42 It is a notable 'universal' of chan sites that child pornography and 'loli' are persistent on all geo-regional iterations and variations of 4 chan.

43 Jean Laplanche and J-B Pontalis, op. cit., I973/I988, pp. 404-407

44 Donald Winnicott, Playing and Reality, London: Routledge, I97I/I999, p. 3 I.

45 Masud Khan, op. cit, p. 222. 